\title{
Estrutura do dossel, consumo e desempenho animal em pastos de capim-marandu sob lotação contínua
}

\author{
[Sward structure, herbage intake and animal performance on marandu palisadegrass \\ pastures subjected to continuous stocking] \\ C.C.L. Paula ${ }^{1}$, V.P.B. Euclides ${ }^{2}$, D.B. Montagner ${ }^{2}$, B. Lempp ${ }^{3}$, \\ G.S. Difante ${ }^{4}$, M.N. Carloto \\ ${ }^{1}$ Aluna de pós-graduação - Campo Grande, MS \\ ${ }^{2}$ Embrapa Gado de Corte - Campo Grande, MS \\ ${ }^{3}$ Universidade Federal da Grande Dourados - Dourados, MS \\ ${ }^{4}$ Universidade Federal do Rio Grande do Norte - Natal, RN
}

\begin{abstract}
RESUMO
Avaliaram-se o valor nutritivo, a estrutura do dossel, a ingestão de forragem e a produção animal de novilhos em pastos de capim-marandu submetidos a três intensidades de pastejo. $\mathrm{O}$ delineamento experimental foi de blocos completos ao acaso, com duas repetições e três intensidades de pastejo, representadas pelas alturas do pasto de 15,30 e $45 \mathrm{~cm}$. Mensalmente, os pastos foram amostrados para as estimativas das características estruturais do dossel e o valor nutritivo da forragem. A ingestão de matéria seca pelos animais foi estimada no verão e no outono de 2008. A oferta de forragem decresceu à medida que aumentou a intensidade de pastejo. Pastos manejados com $15 \mathrm{~cm}$ de altura apresentaram maior valor nutritivo e estrutura do dossel mais favorável à apreensão de forragem pelos animais. A oferta limitou a ingestão de forragem no pasto com $15 \mathrm{~cm}$ de altura, consequentemente se verificaram menor ganho de peso e maior taxa de lotação. Foram observados ganhos por área semelhantes nos pastos com 15 e $30 \mathrm{~cm}$, e ganhos mais elevados no pasto com $45 \mathrm{~cm}$. Durante o período das águas, o capim-marandu deve ser utilizado entre 15 e $30 \mathrm{~cm}$ de altura sob lotação contínua.
\end{abstract}

Palavras-chave: Brachiaria brizantha, cerrado, intensidade de pastejo, taxa de lotação, valor nutritivo

\begin{abstract}
The objectives were to evaluate the nutritive value, sward structure, herbage intake and animal performance on marandu palisadegrass pastures subjected to three grazing intensities under continuous stocking. A randomized block design was used, with two replicates and three grazing intensities represented by 15, 30 and $45 \mathrm{~cm}$ sward heights. Monthly, the pastures were sampled to estimate the sward structure and nutritive value, and the animals were weighted. The herbage intake was estimated twice, one in the summer and another during autumn. The forage allowance decreased with the increase of the grazing intensity. Pasture with $15 \mathrm{~cm}$ height presented greatest nutritive value and sward structure more favorable to herbage apprehension by animals. However, the herbage allowance limited the herbage intake by animals on the pasture with $15 \mathrm{~cm}$ height, consequently the average daily gain was lower, but greater stocking rate was utilized. Therefore, the live weight gain per area was similar between the 15 and $30 \mathrm{~cm}$ pastures, and higher than the $45 \mathrm{~cm}$ high pasture. During the wet season, the marandu palisadegrass, subjected to continuous stocking, must be utilized between 15 and $30 \mathrm{~cm}$ height.
\end{abstract}

Keywords: Brachiaria brizantha, grazing intensity, savanna, nutritive value, stocking rate

Recebido em 26 de julho de 2010

Aceito em 10 de agosto de 2011

E-mail: cassialemes@hotmail.com 


\section{INTRODUÇÃO}

Em sistemas de produção animal em pasto, o controle da estrutura do dossel forrageiro é de grande importância, uma vez que condiciona e determina os padrões de eficiência parcial do sistema: crescimento, utilização e conversão (Hodgson, 1990). A essência de manejo consiste em encontrar balanço eficiente entre o crescimento da planta, o seu consumo e a produção animal, para manter estável o sistema de produção (da Silva, 2004).

Segundo Cosgrove (1997), o desempenho animal apresenta dependência direta do consumo diário de forragem, e indireta com os efeitos que o processo de pastejo tem sobre a massa de forragem e a estrutura do dossel. Dessa forma, a prática de manejo adotada influencia diretamente a estrutura do pasto, e esta, por sua vez, influencia o padrão de comportamento dos animais em pastejo e, consequentemente, a ingestão de forragem e produção por animal
(Carvalho et al., 2001; Palhano et al., 2005; Flores et al., 2008).

Baseado no exposto, o objetivo deste trabalho foi avaliar o valor nutritivo, a estrutura do dossel, o consumo de forragem e a produção por animal e por área de pastos de capim-marandu submetidos a três intensidades de pastejo sob lotação contínua.

\section{MATERIAL E MÉTODOS}

O experimento foi realizado na Embrapa Gado de Corte, Campo Grande, MS. Os pastos de capim-marandu foram estabelecidos em novembro de 2000 e, desde novembro de 2005 , estão submetidos à mesma altura de pastejo. O experimento foi realizado de janeiro a dezembro de 2008. A precipitação pluvial e a temperatura média foram registradas, e utilizadas para o cálculo do balanço hídrico. A capacidade de armazenamento de água do solo (CAD) utilizada foi de $75 \mathrm{~mm}$ (Fig. 1).

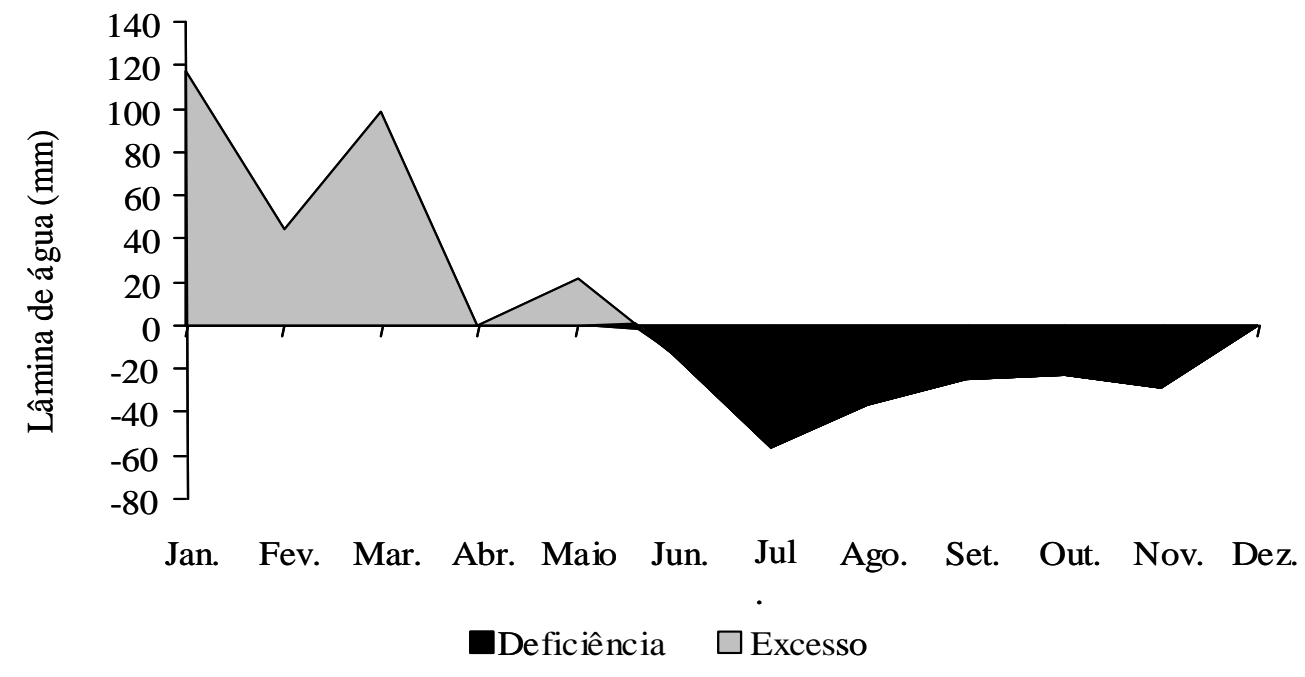

Figura 1. Balanço hídrico mensal no período de janeiro a dezembro de 2008.

O solo da área experimental é o da classe latossolo vermelho distrófico, cuja análise química apresentou os seguintes resultados: 5,0 $\mathrm{pH}\left(\mathrm{CaCl}_{2}\right) ; 35 \%$ de saturação por bases; $3,7 \%$ de saturação por alumínio; 3,7\% matéria orgânica; $1,6 \mathrm{mg} / \mathrm{dm}^{3} \mathrm{P}$ (Mehlich 1); e $46,9 \mathrm{mg} / \mathrm{dm}^{3} \mathrm{~K}$ (Mehlich 1). Em janeiro de 2008, foi feita uma adubação de manutenção com $200 \mathrm{~kg} / \mathrm{ha}$ da fórmula 0-20-20. Foram aplicados $100 \mathrm{~kg} / \mathrm{ha}$ de $\mathrm{N}$ na forma de uréia, divididos em dois períodos: novembro de 2007 e março de 2008. Em abril, foram aplicados $600 \mathrm{~kg} / \mathrm{ha} \mathrm{de}$ gesso agrícola.

A área experimental, com quatro hectares, foi dividida em seis piquetes de 0,67 ha. $\mathrm{O}$ método de pastejo foi o de lotação contínua com taxa de lotação variável. O delineamento experimental foi de blocos ao acaso, com três tratamentos e duas repetições. Os tratamentos foram 
constituídos pela intensidade de pastejo, representada pelas alturas do pasto de 15,30 e $45 \mathrm{~cm}$. O monitoramento da altura dos pastos foi realizado duas vezes por semana, medindo-se com régua 80 pontos aleatórios por piquete. A altura em cada ponto correspondeu à altura média da curvatura das folhas superiores em torno da régua.

A cada 28 dias, cortaram-se 15 amostras de forragem de $1 \mathrm{~m}^{2}$ por piquete, rente ao solo, e a cada cinco amostras formou-se uma composta, que foram separadas em lâmina foliar, colmo (colmo + bainha) e material morto. Posteriormente, foram secas em estufa a $55^{\circ} \mathrm{C}$ e pesadas para obtenção da porcentagem de cada componente morfológico. As amostras de lâmina foliar e do colmo foram moídas a $1 \mathrm{~mm}$ e analisadas para se estimarem os teores de proteína bruta, fibra em detergente neutro, digestibilidade in vitro da matéria orgânica e lignina em detergente ácido, utilizando-se o sistema de espectrofotometria de reflectância no infravermelho proximal (NIRS).

Todos os animais, avaliadores e reguladores, foram pesados a cada 28 dias, com jejum de 16 horas, e os ganhos de peso médios foram estimados para os animais avaliadores. Também foi computado o número de dias de permanência dos animais reguladores no pasto. O número de animais avaliadores e reguladores possibilitou estimar a taxa de lotação e de ganho por área.

O consumo de matéria seca foi estimado no verão e no outono. Foram utilizados o óxido crômico como indicador externo $\left(10 \mathrm{~g}\right.$ de $\mathrm{Cr}_{2} \mathrm{O}_{3}$ animal $^{-1}$. dia) e a digestibilidade in vitro da matéria orgânica da lâmina foliar como indicador interno para determinação da produção fecal dos animais em pastejo. $\mathrm{O}$ fornecimento do indicador externo e a coleta de fezes seguiram a metodologia descrita por Valadares Filho et al. (2005). As fezes foram secas em estufa de ar forçado a $50^{\circ} \mathrm{C}$ e analisadas para estimativa do teor de cromo, conforme metodologia descrita por Willians et al. (1962).

Os dados referentes às características da planta foram agrupados por estação do ano - verão, outono, inverno e primavera - e aqueles referentes aos animais foram agrupados em verão e outono, e analisados por um modelo matemático contendo o efeito aleatório de bloco e os efeitos fixos de altura do dossel, estação do ano e as interações entre eles. Todas as análises foram feitas pelo método dos quadrados mínimos, utilizando-se o procedimento General Linear Model disponível no SAS. Os comandos RANDON e TEST foram usados para a identificação e a realização dos testes apropriados para cada variável dependente. A comparação de médias foi realizada pelo teste Tukey, adotando-se 5\% de probabilidade.

\section{RESULTADOS E DISCUSSÃO}

A altura do pasto permaneceu relativamente estável e dentro das amplitudes planejadas. Os valores médios foram de 14,6 $\pm 1,3 \mathrm{~cm}$; $28,8 \pm 2,2 \mathrm{~cm}$ e $42,1 \pm 3,7 \mathrm{~cm}$, respectivamente, para as metas de 15,30 e $45 \mathrm{~cm}$ de altura.

Não foi observada interação $(\mathrm{P}>0,05)$ de altura do dossel versus estação do ano para as variáveis estudadas. No entanto, o pasto manejado com $15 \mathrm{~cm}$ de altura apresentou menor massa de lâminas foliares (MLF) e maior porcentagem de lâminas foliares $(\mathrm{PF})$ que os pastos manejados com 30 e $45 \mathrm{~cm}$ (Tab. 1). A porcentagem de colmo (PC) aumentou à medida que aumentou a altura do dossel. Controle do alongamento do colmo de capim-marandu, utilizando a maior intensidade de pastejo, também foi encontrado por Flores et al. (2008). A porcentagem de material morto (PM) foi semelhante entre os

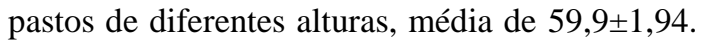
Alto acúmulo de material morto é comumente observado em pastos de capim-marandu sob pastejo contínuo (Euclides et al., 2008; Flores et al., 2008).

A presença de colmos, bainha e material morto no horizonte de pastejo é limitante da profundidade do bocado (Carvalho et al., 2008). Nessa condição, é comum observar aumento no tempo por bocado e redução na taxa de bocados (Palhano et al., 2007; Trindade et al., 2007) e aumento no tempo diário de pastejo (Difante et al., 2009). Assim, as relações folha:colmo (RFC) e folha:não folha (colmo mais material morto, RFNF) tornam-se importantes como indicadores da facilidade de preensão da forragem pelo animal. Pasto manejado com $15 \mathrm{~cm}$ de altura apresentou RFC e RFNF mais altos que pastos manejados com 30 e $45 \mathrm{~cm}$ de altura do dossel (Tab. 1). 
Tabela 1. Médias, erros-padrão da média (EPM) e níveis de significância $(P)$ para massa de lâmina foliares (MLF), porcentagens de lâmina foliar (PF) e de colmo (PC), relações folha:colmo (RFC) e folha:não folha (RFNF), e densidade volumétrica de lâminas foliares (DVLF) em pastos de capimmarandu manejados com diferentes alturas

\begin{tabular}{lccccc}
\hline \multirow{2}{*}{ Variável } & \multicolumn{3}{c}{ Altura $(\mathrm{cm})$} & EPM & P \\
\cline { 2 - 4 } & 15 & 30 & 45 & & \\
\hline MLF (kg/ha de MS) & $983 \mathrm{~b}$ & $1.360 \mathrm{a}$ & $1.451 \mathrm{a}$ & 94,4 & 0,0001 \\
PF (\%) & $28,8 \mathrm{a}$ & $20,9 \mathrm{~b}$ & $17,6 \mathrm{~b}$ & 1,4 & 0,0001 \\
PC (\%) & $14,5 \mathrm{c}$ & $18,5 \mathrm{~b}$ & $21,6 \mathrm{a}$ & 0,8 & 0,0001 \\
RFC & $2,2 \mathrm{a}$ & $1,2 \mathrm{~b}$ & $0,8 \mathrm{~b}$ & 0,14 & 0,0001 \\
RFNF & $0,46 \mathrm{a}$ & $0,30 \mathrm{~b}$ & $0,24 \mathrm{~b}$ & 0,026 & 0,0001 \\
DVLF (kg/ha.cm) & $67 \mathrm{a}$ & $46 \mathrm{~b}$ & $33 \mathrm{c}$ & 3,69 & 0,0001 \\
\hline
\end{tabular}

Médias com letras distintas, na mesma linha, diferem entre si pelo teste Tukey $(\mathrm{P}<0,05)$.

A densidade volumétrica de lâminas foliares (DVLF) decresceu à medida que diminuiu a intensidade de pastejo. Padrões de variação semelhantes para a densidade volumétrica foram encontrados por Fagundes et al. (1999), para pastos de Cynodon spp., e por Sarmento (2003), para pastos de capim-marandu.

Em relação à estação do ano, as maiores MLF, PF e PC foram registradas no verão e no outono, e a menor no inverno (Tab. 2). O inverso foi observado para a PM. A RFC foi maior na primavera quando comparada com as demais estações. Essas variações na estrutura do dossel podem ser explicadas pelas variações nas condições de ambiente e nas adubações nitrogenadas, que influenciaram o fluxo de tecido nas plantas, segundo Paula (2010).

Tabela 2. Médias, erros-padrão da média (EPM) e níveis de significância (P) para massa de lâmina foliar (MLF), porcentagens de lâmina foliar (PF), de colmo (PC) e de material morto (PM), relações folha:colmo (RFC) e densidade volumétrica de lâminas foliares (DVLF) em pastos de capim-marandu segundo a estação de pastejo

\begin{tabular}{lccccc}
\hline Variável & Verão & Outono & Inverno & Primavera & P \\
\hline MLF (kg/ha) & $1.656 \mathrm{a}$ & $1.790 \mathrm{a}$ & $626 \mathrm{c}$ & $986 \mathrm{~b}$ & 0,0001 \\
& $(106)$ & $(130)$ & $(106)$ & $(92)$ & \\
PF $(\%)$ & $28,4 \mathrm{a}$ & $27,2 \mathrm{a}$ & $13,0 \mathrm{c}$ & $20,9 \mathrm{~b}$ & 0,0001 \\
& $(1,6)$ & $(2,0)$ & $(1,4)$ & $(1,4)$ & \\
PC $(\%)$ & $26,5 \mathrm{a}$ & $23,2 \mathrm{~b}$ & $10,1 \mathrm{~d}$ & $13,1 \mathrm{c}$ & 0,0001 \\
& $(1,2)$ & $(1,4)$ & $(1,0)$ & $(1,0)$ & \\
PM (\%) & $45,1 \mathrm{c}$ & $49,6 \mathrm{c}$ & $76,8 \mathrm{a}$ & $65,9 \mathrm{~b}$ & 0,0001 \\
& $(2,2)$ & $(2,7)$ & $(1,9)$ & $(1,9)$ & \\
RFC & $1,2 \mathrm{~b}$ & $1,3 \mathrm{~b}$ & $1,3 \mathrm{~b}$ & $1,9 \mathrm{a}$ & 0,0090 \\
& $(0,17)$ & $(0,20)$ & $(0,15)$ & $(0,15)$ & \\
DVLF (kg/ha.cm) & $68 \mathrm{a}$ & $66 \mathrm{a}$ & $26 \mathrm{~b}$ & $35 \mathrm{~b}$ & 0,0001 \\
& $(4,1)$ & $(5,1)$ & $(4,1)$ & $(3,6)$ & \\
\hline
\end{tabular}

Médias com letras distintas, na mesma linha, diferem entre si pelo teste Tukey $(\mathrm{P}<0,05)$

Valores entre parêntese são o erro-padrão da média.

As lâminas foliares do pasto com $15 \mathrm{~cm}$ apresentaram teores mais baixos de fibra em detergente neutro (FDNF) e lignina em detergente ácido (LDAF) do que os pastos manejados com 30 e $45 \mathrm{~cm}$ (Tab. 3). No entanto, não houve diferenças entre os pastos quanto ao teor de proteína bruta (PBF; $\mathrm{P}=0,1820)$ e digestibilidade in vitro da matéria orgânica (DIVMOF; $\mathrm{P}=0,3752$ ) das lâminas foliares. Já para o colmo, houve acréscimo no teor de proteína bruta (PBC) e na digestibilidade in vitro da matéria orgânica (DIVMOC) e decréscimos 
nos teores de fibra em detergente neutro (FDNC) e lignina em detergente ácido (LDAC) à medida que aumentou a intensidade de pastejo (Tab. 3). $\mathrm{O}$ maior valor nutritivo de pasto mantido a $15 \mathrm{~cm}$ pode ser explicado pela maior rebrotação da planta nesta condição (Cano et al., 2004; Paula, 2010), resultando em folhas e colmos novos. Por outro lado, nos pastos mais altos, as folhas e os colmos rejeitados pelos animais envelheceram, resultando em decréscimo no conteúdo celular e acréscimo na parede celular. Acréscimo no valor nutritivo à medida que decresce a altura do dossel de pastos de gramíneas tropicais também foi encontrado por Carnevalli et al. (2001a,b), Cano et al. (2004) e Palhano et al. (2007).

Tabela 3. Médias, erros-padrão da média (EPM) e níveis de significância $(\mathrm{P})$ para os teores de proteína bruta (PB), fibra em detergente neutro (FDN), lignina em detergente ácido (LDA), e digestibilidade in vitro da matéria orgânica do colmo (DIVMO), em pastos de capim-marandu manejados com diferentes alturas

\begin{tabular}{|c|c|c|c|c|c|}
\hline \multirow{2}{*}{ Variável } & \multicolumn{3}{|c|}{ Altura $(\mathrm{cm})$} & \multirow{2}{*}{ EPM } & \multirow{2}{*}{$\mathrm{P}$} \\
\hline & 15 & 30 & 45 & & \\
\hline \multicolumn{6}{|c|}{ Lâminas foliares } \\
\hline FDN (\%) & $70,9 b$ & $72,5 \mathrm{a}$ & $72,9 a$ & 0,5 & 0,0272 \\
\hline LDA $(\%)$ & $2,7 \mathrm{~b}$ & $3,0 \mathrm{a}$ & $3,1 \mathrm{a}$ & 0,1 & 0,0114 \\
\hline \multicolumn{6}{|c|}{ Colmos } \\
\hline PB (\%) & $5,0 \mathrm{a}$ & $4,2 \mathrm{~b}$ & $3,7 \mathrm{c}$ & 0,1 & 0,0001 \\
\hline FDN (\%) & $78,2 \mathrm{c}$ & $79,5 b$ & $80,9 \mathrm{a}$ & 0,4 & 0,0001 \\
\hline $\operatorname{LDA}(\%)$ & $4,0 \mathrm{c}$ & $4,7 b$ & $5,3 \mathrm{a}$ & 0,1 & 0,0001 \\
\hline DIVMO (\%) & $47,3 \mathrm{a}$ & $43,0 \mathrm{~b}$ & $41,1 b$ & 1,1 & 0,0012 \\
\hline
\end{tabular}

Médias com letras distintas na mesma linha diferem entre si pelo teste Tukey $(\mathrm{P}<0,05)$.

O valor nutritivo da lâmina foliar foi semelhante ao longo do ano, exceto para os teores de PBF, que foram maiores no verão e no outono, e de FDNF, que foi menor na primavera (Tab. 4). O decréscimo na PBF coincidiu com o período de déficit hídrico (Fig. 1), semelhante aos resultados já obtidos por Euclides et al. (2009), de maiores teores de PBF durante o período das águas do que no período seco para os capins marandu, xaraés e piatã. Já para a fração colmo, o maior valor nutritivo foi observado na primavera (Tab. 4). Provavelmente, isto pode ser explicado pela maior renovação de tecidos durante a primavera.

Tabela 4. Médias, erros-padrão da média (EPM) e níveis de significância (P) para teores de proteína bruta (PB), de fibra de detergente neutro (FDN), de lignina em detergente ácido (LDA), e digestibilidade da matéria orgânica (DIVMO), nas lâminas foliares e nos colmos nos pastos de capim-marandu segundo a estação de pastejo

\begin{tabular}{|c|c|c|c|c|c|c|}
\hline Variável & Verão & Outono & Inverno & Primavera & EPM & $\mathrm{P}$ \\
\hline \multicolumn{7}{|c|}{ Lâminas foliares } \\
\hline $\mathrm{PB}(\%)$ & $11,2 \mathrm{a}$ & $10,5 \mathrm{a}$ & $7,9 b$ & $8,8 \mathrm{~b}$ & 0,5 & 0,0002 \\
\hline FDN $(\%)$ & $72,2 \mathrm{a}$ & $73,6 \mathrm{a}$ & $72,6 a$ & $69,9 b$ & 0,6 & 0,0015 \\
\hline \multicolumn{7}{|c|}{ Colmo } \\
\hline $\mathrm{PB}(\%)$ & $4,3 \mathrm{a}$ & $3,8 b$ & $3,8 b$ & $4,4 a$ & 0,2 & 0,0042 \\
\hline FDN $(\%)$ & $80,6 a$ & $79,1 \mathrm{~b}$ & $79,1 b$ & $78,4 \mathrm{~b}$ & 0,4 & 0,0026 \\
\hline LDA & $4,8 \mathrm{a}$ & $4,7 \mathrm{a}$ & $4,8 \mathrm{a}$ & $4,4 b$ & 0,1 & 0,0005 \\
\hline DIVMO & $41,7 \mathrm{~b}$ & $40,4 b$ & $45,7 \mathrm{a}$ & $47,1 \mathrm{a}$ & 1,4 & 0,0012 \\
\hline
\end{tabular}

Médias com letras distintas, na mesma linha, diferem entre si pelo teste Tukey $(\mathrm{P}<0,05)$. 
Com o decréscimo na taxa de acúmulo de forragem durante o inverno (Paula, 2010) e, consequentemente, a baixa MLF no inverno e na primavera (Tab. 2), aliada à pequena dimensão dos piquetes (0,67ha), os animais avaliadores tiveram que ser retirados da área experimental. Dessa forma, estão na Tab. 5 os resultados das variáveis que interferem direta ou indiretamente na ingestão de forragem e, consequentemente, na produção animal, considerando-se apenas o verão e o outono.

Segundo Poppi et al. (1987), a ingestão de forragem é determinada por fatores nutricionais e não nutricionais. Os nutricionais são os relacionados ao valor nutritivo da forragem e aos metabólicos. Os não nutricionais são os associados ao comportamento ingestivo dos animais. Neste contexto, a oferta de forragem e a estrutura do dossel podem tornar-se fatores limitantes ao consumo de forragem pelos animais em pastejo (Stobbs, 1973; Euclides et al., 2000; Brâncio et al., 2003a; Palhano et al., 2007; Trindade et al., 2007).

A altura do dossel e a estação do ano não influenciaram as variáveis associadas $(\mathrm{P}>0,05)$ ao valor nutritivo da forragem. As médias e seus erros-padrão para os teores de PB, FDNF, LDAF e DIVMOF foram, respectivamente, de $10,9 \pm 0,6 \% ; 72,9 \pm 0,8 \% ; 2,9 \pm 0,1 \%$ e $59,9 \pm 1,1 \%$.

Houve decréscimos nas ofertas (kg de MS/100 $\mathrm{kg}$ de $\mathrm{PV}$ ) de matéria seca (OMS) e de lâminas foliares (OLF) à medida que aumentou a altura do dossel, em consequência dos acréscimos nas taxas de lotação (TL) utilizadas para manter as alturas de 45, 30 e $15 \mathrm{~cm}$ do dossel (Tab. 5). Por outro lado, o pasto manejado a $15 \mathrm{~cm}$ apresentou maiores DVLF, PF, RFC e RFNF do que os demais (Tab. 5). Uma vez que as RFC e RFNF são indicativos da facilidade de seleção (Euclides et al., 2000; Brâncio et al., 2003b) e a densidade de forragem indicativo da facilidade apreensão (Carvalho et al., 1999) da forragem pelo animal em pastejo, o pasto mantido a $15 \mathrm{~cm}$ de altura apresentou características estruturais mais favoráveis ao pastejo.

Os animais no pasto com $30 \mathrm{~cm}$ de altura apresentaram maior ingestão de matéria seca (IMS) do que aqueles no pasto com $15 \mathrm{~cm}$, e a IMS no pasto com $45 \mathrm{~cm}$ não diferiu da IMS nas demais alturas (Tab. 5). Este resultado assemelha-se ao de Sarmento (2003), em que o consumo de capim-marandu apresentou um platô entre 20 e $40 \mathrm{~cm}$ de altura do dossel.

Independentemente da altura, os pastos de capim-marandu não apresentaram limitações no valor nutritivo para interferir na ingestão de forragem. A menor IMS foi observada no pasto com $15 \mathrm{~cm}$ de altura (Tab. 5), portanto a estrutura do dossel também não limitou a ingestão de forragem. Assim, provavelmente, o maior limitante da IMS pelos animais no pasto manejado a $15 \mathrm{~cm}$ foi a OLF. Uma vez que o consumo máximo é obtido quando a oferta é de pelo menos três vezes o potencial de ingestão do animal (Carvalho et al., 2001), neste caso a OFL foi de cerca de duas vezes o potencial de consumo dos animais.

Apesar das diferenças nas IMS, não houve efeito significativo (Tab. 5) no ganho médio diário de peso (GMD. A média de ganho de peso foi semelhante à encontrada por Euclides et al. (2009) em pastos de capim-marandu, durante três períodos das águas. Independentemente da altura de manejo, o valor nutritivo da lâmina foliar foi satisfatório e condizente com a produção por animal - $11 \%$ de PB e $60 \%$ de DIVMO. Variações nos ganhos de peso foram consequência, portanto, da ingestão de matéria seca, determinada pela oferta de forragem.

O ganho de peso por área foi maior para os pastos manejados a 15 e $30 \mathrm{~cm}$. Isso se atribui à compensação de menores ganhos com maiores taxas de lotação. Apesar de menor IMS e decréscimo de $150 \mathrm{~g} / \mathrm{animal} /$ dia no pasto com $15 \mathrm{~cm}$, o aumento da TL de 0,5 novilhos/ha/dia foi o suficiente para apresentar a mesma produtividade que o pasto $\mathrm{com} 30 \mathrm{~cm}$ de altura. Assim, se a meta do sistema de produção for otimizar a eficiência de pastejo e o aproveitamento da forragem produzida, a altura deve ser de $15 \mathrm{~cm}$; no entanto, se o foco for a produção por animal, a altura deve ser de $30 \mathrm{~cm}$. Por outro lado, apesar da IMS e do GMD satisfatórios no pasto manejado a $45 \mathrm{~cm}$, a TL utilizada para manter esta meta foi baixa, resultando na baixa utilização da forragem produzida e, consequentemente, no menor ganho por área. 
Tabela 5. Médias, erros-padrão da média (EPM) e nível de significância $(\mathrm{P})$ para a ingestão de matéria seca (IMS), ganho médio diário de peso (GMD), taxa de lotação (TL), produtividade animal, massa de lâminas foliares (MLF), ofertas de matéria seca (OMS) e de lâminas foliares (OLF), densidade volumétrica de lâminas foliares (DVLF), porcentagens de lâmina foliar (PF) e de colmo (PC), relações folha: colmo (RFC) e folha:não folha (RFNF), para pastos de capim-marandu manejados com diferentes alturas

\begin{tabular}{|c|c|c|c|c|c|}
\hline \multirow{2}{*}{ Variável } & \multicolumn{3}{|c|}{ Altura } & \multirow{2}{*}{ EPM } & \multirow{2}{*}{$\mathrm{P}$} \\
\hline & 15 & 30 & 45 & & \\
\hline \multicolumn{6}{|c|}{ Variável relacionada ao animal } \\
\hline IMS (kg de MS 100kg de $\mathrm{PV}^{-1}$ ) & $2,07 \mathrm{~b}$ & $3,04 \mathrm{a}$ & $2,7 \mathrm{ab}$ & 0,18 & 0,0499 \\
\hline GMD (kg) & $0,615 \mathrm{a}$ & $0,765 \mathrm{a}$ & $0,775 \mathrm{a}$ & 0,06 & 0,0883 \\
\hline TL (UA) & $2,8 \mathrm{a}$ & $2,5 \mathrm{ab}$ & $2,0 \mathrm{~b}$ & 0,20 & 0,0264 \\
\hline Produtividade ( $\mathrm{kg} \mathrm{ha}^{-1}$.período) & $330 \mathrm{a}$ & $335 \mathrm{a}$ & $240 \mathrm{~b}$ & 9,2 & 0,0374 \\
\hline \multicolumn{6}{|c|}{ Variável relacionada ao pasto } \\
\hline MLF (kg ha ${ }^{-1}$ de MS) & $1170 \mathrm{~b}$ & $1510 \mathrm{a}$ & 1790a & 156 & 0,0330 \\
\hline OMS (kg de MS $100 \mathrm{~kg}$ de $\mathrm{PV}^{-1}$ ) & $13,4 \mathrm{c}$ & $28,6 \mathrm{~b}$ & $58,7 \mathrm{a}$ & 6,2 & 0,0006 \\
\hline OLF (kg de MS 100kg de $\mathrm{PV}^{-1}$ ) & $4,6 \mathrm{c}$ & $7,7 \mathrm{~b}$ & $14,1 \mathrm{a}$ & 1,2 & 0,0151 \\
\hline $\operatorname{DVLF}\left(\mathrm{kg} \mathrm{ha}^{-1} \cdot \mathrm{cm}\right.$ de MS) & $81,2 \mathrm{a}$ & $52,6 \mathrm{~b}$ & $41,3 b$ & 4,9 & 0,0001 \\
\hline $\mathrm{PF}(\%)$ & $34,7 \mathrm{a}$ & $26,4 b$ & $22,3 b$ & 2,0 & 0,0006 \\
\hline RFC & $1,83 \mathrm{a}$ & $1,08 \mathrm{~b}$ & $0,75 c$ & 0,09 & 0,0001 \\
\hline RFNF & $0,54 \mathrm{a}$ & $0,37 \mathrm{~b}$ & $0,30 \mathrm{~b}$ & 0,04 & 0,0005 \\
\hline
\end{tabular}

Médias seguidas por letras iguais não diferem entre si pelo teste de Tukey, a 5\% de probabilidade.

Em relação à estação do ano, não houve diferença $(\mathrm{P}>0,05)$ para as variáveis estudadas, exceto para a taxa de lotação $(\mathrm{P}=0,0225)$, que foi maior durante o verão do que no outono, sendo, em média, 2,8 e 2,2UA/ha, respectivamente. Isto se deve ao fato de haver maior acúmulo de forragem durante o verão, segundo Paula (2010), consequentemente maior número de animais foi utilizado para manter a altura pretendida.

\section{CONCLUSÕES}

A intensidade de pastejo modifica de forma significativa a estrutura do dossel e o valor nutritivo da forragem. A oferta de forragem no pasto manejado a $15 \mathrm{~cm}$ limita a ingestão diária de forragem pelos animais. $\mathrm{O}$ ganho de peso por área é menor no pasto de capim-marandu manejado a $45 \mathrm{~cm}$. O capim-marandu, sob lotação contínua, deve ser utilizado entre 15 e $30 \mathrm{~cm}$ de altura, durante o período das águas.

\section{AGRADECIMENTOS}

À FUNDECT, pelo financiamento parcial do experimento e pelas bolsas de mestrado da primeira e sexta autoras; ao CNPq, pela bolsa de pesquisa da segunda e quarta autoras e de DCR da quinta autora.

\section{REFERÊNCIAS}

BRÂNCIO, P.A.; EUCLIDES, V.P.B.; NASCIMENTO Jr., D. et al. Avaliação de três cultivares de Panicum maximum Jacq. sob pastejo: comportamento ingestivo de bovinos. Rev. Bras. Zootec., v.32, p.1045-1053, 2003a.

BRÂNCIO, P.A.; NASCIMENTO Jr., D.; EUCLIDES, V.P.B. et al. Avaliação de três cultivares de Panicum maximum Jacq. sob pastejo: composição da dieta, consumo de matéria seca e ganho de peso animal. Rev. Bras. Zootec., v.32, p.1037-1044, 2003 b.

CANO, C.C.P.; CECATO, U.; CANTO, M.W. et al. Produção de forragem do capim-tanzânia (Panicum maximum Jacq. cv. Tanzânia-1) pastejado em diferentes alturas. Rev. Bras. Zootec., v.33, p.19491958, 2004.

CARNEVALLI, R.A.F.; DA SIIVA, S.C.; CARVALHO, C.A.B. et al. Desempenho de ovinos e respostas de pastagens de coastcross (Cynodon spp.) submetidas a regimes de desfolha sob lotação contínua. Pesqui. Agropecu. Bras., v.36, p.919-927, 2001a.

CARNEVALLI, R.A.F.; DA SILVA, S.C.; FAGUNDES, J.L. et al. Desempenho de ovinos e respostas de pastagens de Tifton-85 (Cynodon spp.) submetidas a regimes de desfolha sob lotação contínua. Sci. Agric., v.58, p.7-15, 2001 b.

CARVALHO, P.C.F.; GONDA, H.L.; WADE, M.H. et al. Características estruturais do pasto e o consumo de forragem: o que pastar, quanto pastar e como mover para encontrar o pasto. In: MANEJO ESTRATÉGICO DA PASTAGEM, 4., 2008, Viçosa, MG. Anais... Viçosa, MG: UFV, 2008. p.101-130. 
CARVALHO, P.C.F.; MARÇAL, G.K.; RIBEIRO FILHO, H.M.N. et al. Pastagens altas podem limitar o consumo dos animais. In: REUNIÃO ANUAL DA SOCIEDADE BRASILEIRA DE ZOOTECNIA, 38. 2001, Piracicaba, SP. Anais... Piracicaba, SP: Sociedade Brasileira de Zootecnia, 2001. p.853-871.

CARVALHO, P.C.F.; PRACHE, S.; DAMASCENO, J.C. O processo do pastejo: desafios da procura e apreensão da forragem pelo herbívoro. In: REUNIÃO ANUAL DA SOCIEDADE BRASILEIRA DE ZOOTECNIA, 36., 1999, Porto Alegre, RS. Anais... Porto Alegre: Sociedade Brasileira de Zootecnia, 1999. p.253-268.

COSGROVE, G. P. Grazing behaviour and forage intake. In: INTERNATIONAL SYMPOSIUM ON ANIMAL PRODUCTION UNDER GRAZING, 1997, Viçosa, MG. Anais... Viçosa, MG: UFV, 1997. p.5980.

da SILVA, S.C. Fundamentos para manejo do pastejo de plantas forrageiras dos gêneros Brachiaria e Panicum. In: SIMPÓSIO SOBRE MANEJO ESTRATÉGICO DA PASTAGEM, 2., 2004, Viçosa, MG. Anais... Viçosa, MG:UFV, 2004. p.347-385.

DIFANTE, G.S.; EUCLIDES, V.P.B.; NASCIMENTO Jr., D. et al. Ingestive behaviour, herbage intake and grazing efficiency of beef cattle steers on tanzânia guineagrass subjected to rotational stocking managements. Rev. Bras. Zootec., v.38, p.1001-1008, 2009.

EUCLIDES, V.P.B.; CARDOSO, E.G.; MACEDO, M.C.M. et al. Consumo voluntário de Brachiaria decumbens cv. Basilisk e Brachiaria brizantha cv. Marandu sob pastejo. Rev. Bras. Zootec., v.29, p.22002208, 2000

EUCLIDES, V.P.B.; MACEDO, M.C.M.; VALLE, C.B. et al., Valor nutritivo da forragem e produção animal em pastagens de Brachiaria brizantha. Pesq. Agropec. Bras., v.44, p.98-106, 2009.

EUCLIDES, V.P.B., MACEDO, M.C.M., VALLE, C.B. et al. Produção de forragem e características da estrutura do dossel de cultivares de Brachiaria brizantha sob pastejo. Pesq. Agropec. Bras., v.43, p.1805-1812, 2008.

FAGUNDES, J.L.; DA SILVA, S.C.; PEDREIRA, C.G.S. et al. Intensidades de pastejo e a composição morfológica de pastos de Cynodon spp. Sci. Agric., v.56, p.1-14, 1999.

FLORES, R.S.; EUCLIDES, V.P.B.; ABRÃO, M.P.C. et al. Desempenho animal, produção de forragem e características estruturais dos capins marandu e xaraés submetidos a intensidades de pastejo. Rev. Bras. Zootec., v.37, p.1355-1365, 2008.
HODGSON, J. Grazing management: science into practice. Hong Kong: Longman Scientific \& Technical, 1990. 203 p

PALHANO, A.L.; CARVALHO, P.C.F.; DITTRICH, J.R. et al. Estrutura da pastagem e padrões de desfolhação em capim-mombaça em diferentes alturas do dossel forrageiro. Rev. Bras. Zootec., v.34, p.18601870,2005 .

PALHANO, A.L.; CARVALHO, P.C.F.; DITTRICH, J.R. et al. Características do processo de ingestão de forragem por novilhas holandesas em pastagem de capim-mombaça. Rev. Bras. Zootec., v.36, p.10141021, 2007.

PAULA, C.C.L. Produção animal, morfogênese $e$ acúmulo de forragem do capim-marandu submetidos à intensidades de pastejo sob lotação contínua. 2010. 39f. Dissertação (Mestrado em Ciência Animal) Universidade Federal de Mato Grosso do Sul, Campo Grande, MS.

POPPI, D.P.; HUGHES, T.P.; L'HUILLIER, P.J. Intake of pasture by grazing ruminants. In: NICOL, A.M. (Ed.). Livestock feeding on pasture. Hamilton: New Zealand Society Of Animal Production, 1987. p.55-64. (Occasional Publication, $\left.\mathrm{N}^{\circ} 10\right)$.

SARMENTO, D.O.L. Comportamento ingestivo de bovinos em pastos de capim-marandu submetidos a regimes de lotação contínua. 2003. 76f. Dissertação (Mestrado em Agronomia) - Escola Superior de Agricultura Luiz de Queiroz, Universidade de São Paulo, Piracicaba, SP.

STOBBS, T.H. The effect of plant structure on the intake of tropical pastures. II. Differences in sward structure, nutritive value, and bite size of animals grazing Setaria anceps and Chloris gayana at various stages of growth. Austr. J. Agric. Res., v.24, p.821829,1973

TRINDADE, J.K.; DA SILVA, S.C.; SOUZA Jr., S.J. et al. Composição morfológica da forragem consumida por bovinos de corte durante o rebaixamento do capim-marandu submetido a estratégias de pastejo rotativo. Pesqui. Agropecu. Bras., v.42, p.883-890, 2007.

VALADARES FILHO, S.C.; PAULINO, P.V.R.; SAINZ, R.D. Desafios metodológicos para determinação das exigências nutricionais de bovinos de corte no Brasil. In: REUNIÃO ANUAL DA SOCIEDADE BRASILEIRA DE ZOOTECNIA, 42., 2005, Goiânia, GO. Anais... Goiânia, GO: Sociedade Brasileira de Zootecnia, 2005. p.261- 287.

WILLIANS, C.H.; DAVID, D.J.; ISMAA, O. The determination of chromic oxide in feces samples by atomic absorption spectrophotometry. J. Agric. Sci., v.59, p.81-85, 1962 . 